\title{
Hubungan Pendidikan, Usia dan Status Pekerjaan dengan Pemakaian Alat Kontrasepsi dalam Rahim (AKDR) di Puskesmas Pedamaran Kecamatan Pedamaran Kabupaten Oki Tahun 2019
}

\author{
Esti Agustina ${ }^{1,2 *}$, Merisa Riski ${ }^{3}$, Rini Gustina Sari ${ }^{4}$ \\ ${ }^{1,3,4}$ Program Studi DIV Kebidanan Fakultas Kebidanan dan Keperawatan, Universitas Kader Bangsa Palembang \\ ${ }^{2}$ Puskesmas Pedamaran Kecamatan Pedamaran Kabupaten OKI \\ *Correspondence email: hendriesti@gmail.com
}

\begin{abstract}
Abstrak. Program keluarga berencana saat ini sangat dibutuhkan untuk mencegah kehamilan yang tidak diinginkan dan untuk meningkatkan kesehatan serta kesejahteraan ibu dan anak. Penelitian ini untuk mengetahui hubungan pendidikan, usia dan status pekerjaan secara simultan dengan Pemakaian Alat Kontrasepsi Dalam Rahim (AKDR) di Puskesmas Pedamaran Kecamatan Pedamaran Kabupaten OKI Tahun 2020. Penelitian ini merupakan penelitian kuantitatif jenis penelitian deskriptif dengan menggunakan pendekatan cross sectional dengan jumlah sampel 98 responden dengan tehnik systematic random sampling. Pengumpulan data dilakukan dengan melihat dan mencatat data akseptor KB di rekam medis ada variabel pendidikan, usia dan status pekerjaan menggunakan lembar cheklist yang di rancang oleh peneliti. Penelitian ini dilakukan pada bulan Maret sampai Agustus 2020. Berdasarkan analisis didapatkan bahwa terdapat hubungan yang signifikan antara pendidikan $(\rho$ value 0,027), usia ( $\rho$ value 0,005), status pekerjaan ( $\rho$ value 0,026) dengan pemakaian alat kontrasepsi dalam rahim (AKDR) di Puskesmas Pedamaran Kecamatan Pedamaran Kabupaten OKI Tahun 2020. Kesimpulan dalam penelitian ini dapat diketahui bahwa terdapat hubungan antara pendidikan, usia dan status pekerjaan dengan pemakaian alat kontrasepsi dalam rahim (AKDR) di Puskesmas Pedamaran Kecamatan Pedamaran Kabupaten OKI Tahun 2019.
\end{abstract}

Kata kunci: AKDR; Pendidikan; Pekerjaan; Usia

\begin{abstract}
Family planning programs are now urgently needed to prevent unwanted pregnancies and to improve the health and well-being of mothers and children. This study is to determine the relationship between education, age and work status simultaneously with the use of intrauterine devices (IUD) at Pedamaran Public Health Center, Pedamaran District, OKI Regency in 2019. This research is a quantitative research type descriptive research using a cross sectional approach with a sample size of 98 respondents. with systematic random sampling technique. The data was collected by looking at and recording data on family planning acceptors in the medical records where there were variables of education, age and work status using a checklist designed by the researcher. This research was conducted from March to August 2020. Based on the analysis, it was found that there was a significant relationship between education ( $\rho$ value 0.027), age ( $\rho$ value 0.005), work status ( $\rho$ value 0.026) and the use of intrauterine contraceptives (IUD) in Pedamaran Public Health Center, Pedamaran District, OKI Regency in 2020. The conclusion in this study can be seen that there is a relationship between education, age and employment status with the use of intrauterine contraceptives (IUD) at Pedamaran Puskesmas Pedamaran District, OKI Regency in 2019.
\end{abstract}

Keywords: Age; Education; IUD; Profession

\section{PENDAHULUAN}

Program keluarga berencana saat ini sangat dibutuhkan untuk mencegah kehamilan yang tidak diinginkan dan untuk meningkatkan kesehatan serta kesejahteraan ibu dan anak. Metode kontrasepsi jangka panjang (MKJP) adalah merupakan metode kontrasepsi mempunyai tingkat efektifitas tinggi. Metode ini antara lain implan, Intra Uterine Device (IUD), metode operasi wanita (MOW) atau tubektomi dan metode operasi pria (MOP) atau vasektomi. Adapun kecenderungan pasangan usia subur (PUS) dalam memilih metode kontrasepsi non MKJP masih tinggi meskipun dengan potensi kegagalan kontrasepsi yang besar, baik dikarenakan penggunaan yang salah, pemakaian yang tidak teratur dan efek samping yang membuat tidak nyaman (Wati dan Wulandari, 2017).

Prevalensi penggunaan kontrasepsi di Indonesia berdasarkan hasil Riskesdas terdapat Wanita Usia Subur
(WUS) dengan usia 15-49 tahun status kawin sebanyak $59,7 \%$ menggunakan kontrasepsi tetapi $24,8 \%$ tidak menggunakan kontrasepsi (Herawati, I. 2011).

Intra Uterine Device (IUD) adalah metode ketiga yang paling umum digunakan sebesar $11,41 \%$. Intra Uterine Device (IUD) merupakan kontrasepsi yang digunakan oleh $18 \%$ wanita usia reproduktif di Asia dan lebih dari 40\% di China (Joshi et al, 2015).

Pendidikan merupakan tolak ukur seseorang untuk mengetahui informasi dan pengetahuan tentang kesehatan contohnya alat kontrasepsi. Semakin tinggi pendidikan seseorang akan lebih paham untuk menentukan alat kontrasepsi yang dibutuhkan seorang wanita dalam waktu panjang yaitu pemilihan alat kontrasepsi IUD (Rozi et al, 2017).

Menurut penelitian yang dilakukan oleh Kunang (2016) diperlukan sosialisasi oleh petugas kesehatan tentang pemilihan jenis alat kontrasepsi baik keuntungan 
maupun kerugian dengan memperhatikan karakteristik responden melalui penyuluhan dengan menggunakan bahasa di sertai demonstrasi tentang jenis alat kontrasepsi yang mudah di fahami untuk membantu akseptor KB dengan pendidikan yang rendah agar memahami materi yang di sampaikan petugas kesehatan.

Penelitian yang berjudul "Hubungan Usia, Pendidikan dan Paritas dengan Penggunaan AKDR di Puskesmas Doloduo Kabupaten Bolaang Mongondow Tahun 2016", mengatakan bahwa ada hubungan antara usia dengan penggunaan IUD dikarenakan responden dengan usia $<19$ tahun sedikit menggunakan kontrasespi AKDR, karena suami tidak mengizinkan istri menggunakan kontrasepsi, dukungan dari suami sangat di perlukan karena tanpa adanya dukungan suami rasa nyaman untuk menggunakan kontrasepsi tidak akan didapatkan (Ibrahim, 2019).

Menurut penelitian Junita, D, 2018, yang berjudul faktor-faktor yang berhubungan dengan penggunaan kontrasepsi AKDR di BPS.Rosmala Aini Palembang, didapatkan hasil uji statistik $p$ value $=0,025$ yang berarti ada hubungan yang bermakna antara pekerjaan dengan penggunaan kontrasepsi AKDR.

Berdasarkan penelitian yang berjudul faktor-faktor yang berhubungan dengan pemilihan alat kontrasepsi dalam rahim (AKDR) bagi akseptor $\mathrm{kb}$ di puskesmas jailolo, bekerja atau tidak bekerja tidak memengaruhi seorang akseptor dalam pemilihan kontrasepsi, khususnya AKDR, sebab kontrasepsi ini tidak mengganggu aktivitas sehari-hari (Bernadus et al, 2013).

Penelitian ini bertujuan untuk mengidentifikasi hubungan pendidikan, usia, status pekerjaan dengan pemakaian alat kontrasepsi dalam rahim (AKDR).

\section{METODE}

Penelitian ini adalah bersifat kuantitatif dengan pendekatan cross sectional, yang bertujuan untuk mengetahui hubungan variabel independen yaitu Pendidikan, Usia dan Status Pekerjaan dengan variabel dependen yaitu Pemakaian Alat Kontrasepsi Dalam Rahim (AKDR). Penelitian di lakukan pada bulan Penelitian dilaksanakan pada bulan Maret s/d bulan Agustus 2020.

Populasi dalam penelitian ini adalah semua semua wanita usia subur yang merupakan peserta KB aktif yang berkunjung di Wilayah Kerja Puskesmas Pedamaran Kecamatan Pedamaran Tahun 2019 yang diperkirakan berjumlah 4.415 orang.

Sampel penelitian diambil dengan menggunakan random sampling dengan teknik systematic random sampling atau pengambilan sample secara acak sistematis dengan cara membagi jumlah atau anggota populasi dengan perkiraan sample yang diinginkan, hasilnya interval sample. Sampel pada pada penelitian ini adalah seluruh dari wanita usia subur yang merupakan peserta $\mathrm{KB}$ aktif yang berkunjung di wilayah kerja Puskesmas Pedamaran Kecamatan Pedamaran Tahun 2019 dengan jumlah sampel 98 orang.

\section{HASIL DAN PEMBAHASAN}

\section{Analisis Univariat}

Hasil analisis univariat distribusi frekuensi pemakaian alat kontrasepsi dalam rahim (AKDR) tampak pada tabel 1 .

Tabel 1. Distribusi Frekuensi Pemakaian Alat Kontrasepsi Dalam Rahim (AKDR)

\begin{tabular}{lcc}
\hline \multicolumn{1}{r}{ AKDR } & Frekuensi (f) & Persentase \% \\
\hline Ya & 50 & 51 \\
Tidak & 48 & 49 \\
\multicolumn{1}{c}{ Total } & 98 & 100 \\
\hline
\end{tabular}

Sumber: Data diolah

Tabel 1 menunjukkan sebagian besar responden yang menggunakan AKDR sebanyak 50 responden $(51 \%)$.

Tabel 2. Distribusi Frekuensi Pendidikan

\begin{tabular}{ccc}
\hline Pendidikan & Frekuensi (f) & Persentase \% \\
\hline Tinggi & 40 & 40,8 \\
Sedang & 40 & 40,8 \\
Rendah & 18 & 18,4 \\
Total & 98 & 100 \\
\hline
\end{tabular}

Sumber: Data diolah

Tabel 2 menunjukkan sebagian besar responden yang berpendidikan tinggi sebanyak 40 responden $(40,8 \%)$ dan berpendidikan sedang sebanyak 40 responden $(40,8 \%)$.

Tabel 3. Distribusi Frekuensi Usia

\begin{tabular}{lccc}
\hline \multicolumn{1}{c}{ Usia } & Frekuensi (f) & Persentase \% \\
\hline Muda & 48 & 49 \\
Tua & 50 & 51 \\
& Total & 98 & 100 \\
\hline
\end{tabular}

Sumber: Data diolah

Tabel 3 menunjukkan sebagian besar responden dengan usia tua sebanyak 50 responden (51\%).

Tabel 4. Distribusi Frekuensi Status Pekerjaan

\begin{tabular}{ccc}
\hline \multicolumn{1}{c}{ Status Pekerjaan } & Frekuensi (f) & Persentase \% \\
\hline Bekerja & 47 & 48 \\
Tidak Bekerja & 51 & 52 \\
\multicolumn{1}{c}{ Total } & 98 & 100 \\
\hline
\end{tabular}

Sumber: Data diolah

Tabel 4 menunjukkan sebagian besar responden yang tidak bekerja sebanyak 51 responden $(52 \%)$.

\section{Analisis Bivariat}

Hasil analisis bivariat hubungan pendidikan dengan AKDR, dapat dilihat pada tabel 5. 
Esti Agustina, Merisa Riski dan Rini Gustina Sari, Hubungan Pendidikan, Usia dan Status Pekerjaan dengan Pemakaian Alat Kontrasepsi dalam Rahim (AKDR) di Puskesmas Pedamaran Kecamatan Pedamaran Kabupaten Oki Tahun 2019

Tabel 5. Distribusi Frekuensi Pendidikan Dengan Pemakaian Alat Kontrasepsi Dalam Rahim (AKDR)

\begin{tabular}{|c|c|c|c|c|c|c|c|}
\hline \multirow{3}{*}{ Pendidikan } & \multicolumn{4}{|c|}{ AKDR } & \multirow{2}{*}{\multicolumn{2}{|c|}{ Jumlah }} & \multirow{3}{*}{$\begin{array}{c}P \\
\text { Value }\end{array}$} \\
\hline & \multicolumn{2}{|c|}{ Ya } & \multicolumn{2}{|c|}{ Tidak } & & & \\
\hline & f & $\%$ & f & $\%$ & f & $\%$ & \\
\hline Tinggi & 26 & 26.5 & 14 & 14,3 & 40 & 100 & \\
\hline Sedang & 19 & 19,4 & 21 & 21,4 & 40 & 100 & 0,027 \\
\hline Rendah & 5 & 5,1 & 13 & 13,3 & 18 & 100 & \\
\hline Jumlah & 50 & & 48 & & 98 & 100 & \\
\hline
\end{tabular}

Sumber: Data diolah

Tabel 5 menunjukkan persentase AKDR lebih tinggi pada ibu yang berpendidikan tinggi dibandingkan ibu yang berpendidikan sedang dan rendah $(26,5 \%)$.
Hasil uji chi square didapatkan p-value 0,027, artinya ada hubungan yang bermakna antara frekuensi pendidikan dengan AKDR.

Tabel 6. Distribusi Frekuensi Usia Dengan Pemakaian Alat Kontrasepsi Dalam Rahim (AKDR)

\begin{tabular}{|c|c|c|c|c|c|c|c|}
\hline \multirow{3}{*}{ Usia } & \multicolumn{4}{|c|}{ AKDR } & \multirow{2}{*}{\multicolumn{2}{|c|}{ Jumlah }} & \multirow{3}{*}{$\underset{\text { Value }}{P}$} \\
\hline & \multicolumn{2}{|c|}{ Ya } & \multicolumn{2}{|c|}{ Tidak } & & & \\
\hline & f & $\%$ & f & $\%$ & f & $\%$ & \\
\hline Muda & 17 & 35.4 & 31 & 64.6 & 48 & 100 & 0,005 \\
\hline Tua & 33 & 66.0 & 17 & 34.0 & 50 & 100 & \\
\hline Jumlah & 50 & & 48 & & 98 & 100 & \\
\hline
\end{tabular}

Sumber: Data diolah

Tabel 6 menunjukkan persentase AKDR lebih tinggi pada ibu dengan usia beresiko dibandingkan dengan ibu dengan usia tidak beresiko $(60,3 \%)$.
Hasil uji chi square didapatkan p-value 0,005, artinya ada hubungan yang bermakna antara frekuensi usia dengan AKDR.

Tabel 7. Distribusi Frekuensi Status Pekerjaan Dengan Pemakaian Alat Kontrasepsi Dalam Rahim (AKDR)

\begin{tabular}{|c|c|c|c|c|c|c|c|}
\hline \multirow{3}{*}{ Status Pekerjaan } & \multicolumn{4}{|c|}{ AKDR } & \multirow{2}{*}{\multicolumn{2}{|c|}{ Jumlah }} & \multirow{3}{*}{$\begin{array}{c}P \\
\text { Value }\end{array}$} \\
\hline & \multicolumn{2}{|c|}{$\mathbf{Y a}$} & \multicolumn{2}{|c|}{ Tidak } & & & \\
\hline & f & $\%$ & f & $\%$ & f & $\%$ & \\
\hline Bekerja & 30 & 63,8 & 17 & 36,2 & 47 & 100 & 0,026 \\
\hline Tidak Bekerja & 20 & 39,2 & 31 & 60,3 & 51 & 100 & \\
\hline Jumlah & 50 & & 48 & & 98 & 100 & \\
\hline
\end{tabular}

Sumber: Data diolah

Tabel 7 menunjukkan persentase AKDR lebih tinggi pada ibu dengan usia beresiko dibandingkan dengan ibu dengan usia tidak beresiko $(60,3 \%)$.

Hasil uji chi square didapatkan p-value 0,005, artinya ada hubungan yang bermakna antara frekuensi usia dengan AKDR.

Hasil penelitian menunjukkan bahwa ada hubungan yang bermakna antara pendidikan dengan pemakaian alat kontrasepsi dalam rahim (AKDR). Seseorang dengan berpendidikan akan memiliki pemikiran yang luas dan tinggi terhadap informasi yang didapat di bandingkan dengan sesorang yang berpendidikan rendah. Penelitian ini sejalan dengan (Utami, 2017) bahwa pendidikan merupakan tolak ukur seseorang untuk mengetahui informasi dan pengetahuan tentang kesehatan contohnya alat kontrasepsi. Semakin tinggi pendidikan seseorang akan lebih paham untuk menentukan alat kontrasepsi yang dibutuhkan seorang wanita dalam waktu panjang yaitu pemilihan alat kontrasepsi IUD. Menurut penelitian yang dilakukan oleh Kunang, A. (2016), diperlukan sosialisasi oleh petugas kesehatan tentang pemilihan jenis alat kontrasepsi baik keuntungan maupun kerugian dengan memperhatikan karakteristik responden melalui penyuluhan dengan menggunakan bahasa di sertai demonstrasi tentang jenis alat kontrasepsi yang mudah di fahami untuk membantu akseptor KB dengan pendidikan yang rendah agar memahami materi yang di sampaikan petugas kesehatan Kunang, A. (2016).

Analisis terhadap hubungan usia dengan pemakaian alat kontrasepsi dalam rahim (AKDR) terdapat hubungan yang bermakna. Penelitian ini sesuai dengan

\section{SIMPULAN}

Dari hasil penelitian yang telah di lakukan pada bulan bulan Maret s/d bulan Agustus 2020 di Puskesmas Pedamaran Kecamatan Pedamaran Tahun 2019 dapat disimpulkan:

1. Ada hubungan pendidikan dengan pemakaian alat kontrasepsi dalam rahim (AKDR) di Puskesmas 
Esti Agustina, Merisa Riski dan Rini Gustina Sari, Hubungan Pendidikan, Usia dan Status Pekerjaan dengan Pemakaian Alat Kontrasepsi dalam Rahim (AKDR) di Puskesmas Pedamaran Kecamatan Pedamaran Kabupaten Oki Tahun 2019

Pedamaran Kecamatan Pedamaran Tahun 2019 dengan $\rho$ value 0,027 .

2. Ada hubungan usia dengan pemakaian alat kontrasepsi dalam rahim (AKDR) di Puskesmas Pedamaran Kecamatan Pedamaran Tahun 2019 dengan $\rho$ value 0,005 .

3. Ada hubungan status pekerjaan dengan pemakaian alat kontrasepsi dalam rahim (AKDR) di Puskesmas Pedamaran Kecamatan Pedamaran Tahun 2019 dengan $\rho$ value 0,027 .

\section{DAFTAR PUSTAKA}

Bernadus, J. D., Madianung, A., \& Masi, G. (2013). Faktor-faktor yang berhubungan dengan pemilihan alat kontrasepsi dalam rahim (AKDR) bagi akseptor KB di Puskesmas Jailolo. e-NERS, 1(1).

Herawati, I. (2011). Analisis kematian ibu di Indonesia tahun 2010 berdasarkan data SDKI, Riskesdas, dan laporan rutin kesehatan ibu dan anak. Pertemuan Teknis Kesehatan Ibu, 6.

Ibrahim, W. W., Misar, Y., \& Zakaria, F. (2019). HUBUNGAN USIA, PENDIDIKAN DAN PARITAS DENGAN PENGGUNAAN AKDR DI PUSKESMAS DOLODUO KABUPATEN BOLAANG MONGONDOW. Akademika, 8(1), 35-44.

Junita, D. Faktor-faktor yang Berhubungan dengan Penggunaan Kontrasepsi Akdr (Alat Kontrasepsi dalam Rahim) di BPS Rosmala Aini Palembang Tahun 2018. Scientia Journal, 7(1), 32-42.

Joshi, R., Khadilkar, S., \& Patel, M. (2015). Global trends in use of long-acting reversible and permanent methods of contraception: seeking a balance. International Journal of Gynecology \& Obstetrics, 131, S60-S63.

Kunang, A. (2016). FAKTOR-FAKTOR YANG BERHUBUNGAN DENGAN PENGGUNAAN ALAT KONTRASEPSI IUD PADA AKSEPTOR KB DI WILAYAH KERJA PUSKESMAS TANJUNG KEMALA KABUPATEN TANGGAMUS. Jurnal Ilmiah Kesehatan, 5(10).

Rozi, R., Utami, N. W., \& Lasri, L. (2017). Hubungan antara tingkat pengetahuan terhadap motivasi penggunaan alat kontrasepsi pria pus di desa mulyorejo kecamatan ngantang kabupaten malang. Nursing News: Jurnal Ilmiah Keperawatan, 2(3).

Wati, L. R., \& Wulandari, D. T. (2017). Karakterstik Ibu (Usia, Paritas, Pendidikan, Pengalaman KB) Berhubungan dengan Pemilihan Metode Kontrasepsi. Journal of Issues in Midwifery, I(2), 9-18.

Weni, L., Yuwono, M., \& Idris, H. (2019). Determinan Pemilihan Metode Kontrasepsi Jangka Panjang Pada Akseptor KB Aktif di Puskesmas Pedamaran. Contagion: Scientific Periodical
Journal of Public Health and Coastal Health, l(01). 